Richard B. Lillich/ F. C. Newman

International Human Rights: Problems of Law and Policy

Little, Brown and Company, Boston, Toronto, 1979, XVI, $1030 \mathrm{~S}$.

Die beiden Autoren haben nach langjährigen Erfahrungen mit Kursen über Menschenrechte in amerikanischen Law Schools ein materialreiches 'Coursebook' zusammengestellt, das auch für diejenigen, die nicht zu Zwecken akademischer Lehre mit Menschenrechten befaßt sind, ergiebig ist. Für zwölf Fragestellungen aus dem Bereich des internationalen Menschenrechtsschutzes wird jeweils ein konkretes Geschehen mit Dokumenten wie Zeitungsberichten, Reden verantwortlicher Politiker u. ä. vorgestellt (z. B. Chile und die UNO, Bangladesh und die UNO, Lieutenant-Calley-Fall), ehe kommentierende Bemerkungen und repräsentative Passagen aus der (vorwiegend) völkerrechtlichen Literatur zur Vertiefung ermuntern. Dem Zweck des Buches als einer Arbeitsunterlage entsprechend finden sich zahlreiche weiterführende Fragen, die vom Benutzer beantwortet werden sollen. Sowohl die thematischen Schwerpunkte wie die Literaturauswahl sind auf amerikanische Interessen und Bedürfnisse abgestimmt. Probleme, die für die USAußenpolitik eine Rolle gespielt haben, überwiegen; unter den zu Wort kommenden Autoren finden sich nur wenige Nicht-Amerikaner (Brownlie, Scheuner, Ermacora).

Philip Kunig

\title{
Karl Hammer
}

Weltmission und Kolonialismus. Sendungsideen des 19. Jahrhunderts im Konflikt München, dtv, 1981, 349 S., DM 12,80

"Noch nirgend ist in der Heidenwelt eine europäische Kolonie entstanden ohne die schwersten Ungerechtigkeiten." Diesen Satz aus der Barmer Deputation vom 29. 12. 1884 zitiert Karl Hammer in seinem Band "Weltmission und Kolonialismus". Diese Aussage rund 100 Jahre später anhand des vorliegenden geschichtlichen Materials einer kritischen Prüfung zu unterziehen, wäre allen Fleißes wert gewesen und hätte dazu beitragen können, die heutigen Schwierigkeiten und Probleme damaliger Kolonien und ihr aktuelles Verhältnis zu den ehemaligen Kolonialmächten zu verstehen.

Leider läßt sich der Autor trotz mancher hoffnungsvoller Ansätze nicht ernstlich auf diese Fragestellung ein. Stattdessen bietet er vor allem in Teil I seiner dreiteiligen Untersuchung alten Wein in bloß runderneuerten Schläuchen; d. h. die Erkenntnis, daß es einen Zusammenhang von christlicher Mission und Kolonialismus gegeben hat, ist ebensowenig neu und überraschend, wie die, daß ihr Verhältnis of $t$ auch ein durchaus spannungsgeladenes war.

Was die Lektüre vor allem des ersten Teiles, in dem der Autor sich bemüht, "die verschiedenen Sendungsideen und -kräfte des 19. Jahrhunderts" darzustellen, ärgerlich macht, ist zweierlei. Einmal ist es das ängstliche Bemühtsein, möglichst jedem Aspekt 